\title{
A DECRETAÇÃO DAS OPERAÇÕES DE GARANTIA DA LEI E DA ORDEM NA DEFESA DO ESTADO PELAS FORÇAS ARMADAS
}

\section{THE DECLARATION OF WARRANTY OPERATIONS OF THE LAW AND ORDER IN THE DEFENSE OF THE STATE BY THE ARMED FORCES}

\author{
Jaasiel Gipson da Silva Campos ${ }^{1}$
}

RESUMO: O presente artigo tem como objetivo demonstrar como ocorre a utilização das forças armadas no caso de decretação das operações de garantia da lei e da ordem pelos Chefes dos Poderes Executivo, Legislativo ou Judiciário e mostrar a evolução legislativa que permitiu o emprego dos militares das Forcas Armadas na segurança pública dos Estados-membros. A missão, da garantia da lei e da ordem, a ser desempenhada pelos integrantes dos órgãos de segurança pública é uma questão primária e inerente a cada órgão policial, tais como insculpidos na Constituição Federal de 1988, em seu artigo 144, onde preconiza que a segurança pública, dever do Estado, direito e responsabilidade de todos, é exercida para a preservação da ordem pública e da incolumidade das pessoas e do patrimônio. O objetivo a ser alcançado é proporcionar destaque aos principais pontos sobre o amparo legal e o seu surgimento nas questões de maior relevo quando da utilização das forças armadas na decretação das operações de garantia da lei e da ordem por um dos Chefes dos Três Poderes. Realizar-se-á pesquisa pelo método dedutivo de cunho qualitativo, exploratório e bibliográfico. A aplicação de tropas militares em ações dessa natureza, comprovadamente, em diversos eventos ocorridos no Brasil, afirma-se que o Poder Militar é capaz de neutralizar, temporariamente, os efeitos de uma determinada situação que afete os poderes constitucionais, a lei e a ordem, mas somente uma real atuação integrada de todas as expressões do Poder Nacional será capaz de eliminar os problemas da segurança pública brasileira.

Palavras-chave: Forças armadas, garantias, amparo legal, defesa do Estado.
ABSTRACT:The purpose of this article is to demonstrate how the use of the armed forces occurs in the event of decrees of law and order guarantee operations by the Heads of the Executive, Legislative or Judicial Branches and show the legislative evolution that allowed the use of the Armed Forces public security in the Member States. The task of guaranteeing law and order to be performed by the members of the public security organs is a primary and inherent issue of each police body, as inscribed in the Federal Constitution of 1988, article 144, which public security, the duty of the State, the right and responsibility of all, is exercised for the preservation of public order and the safety of persons and property. The objective to be achieved is to highlight the main points on legal protection and its emergence on the most important issues when using the armed forces in the enactment of law enforcement operations and order by one of the Chiefs of the Three Powers. Research will be carried out by qualitative, exploratory and bibliographic deductive method. The application of military troops to actions of this nature, evidenced in various events in Brazil, states that the Military Power is able to temporarily neutralize the effects of a certain situation that affects the constitutional powers, law and order, but only a real integrated action of all the expressions of the National Power will be able to eliminate the problems of the Brazilian public security.

Keywords: Armed forces, guarantees, legal amparo, defense of the State. 


\section{INTRODUÇÃO}

As Forças Armadas têm o dever constitucional de assegurar e manter ao Estado Brasileiro estabilidade para que desenvolva suas atividades e venha a promover a garantia institucional aos poderes constituintes, sendo composta pelo Exército, Marinha e a Aeronáutica, dotadas de um grande poder armamentista.

Dentro dos princípios do Estado Democrático de Direito às Forças Armadas, constitucionalmente, possuem como pilares básicos de sua organização a hierarquia e na disciplina, são um corpo especial da administração por sua militarização, tendo como chefe imediato o Presidente da República. (FERREIRA FILHO, 2002, p. 235)

Pode-se Destacar a Intervenção federal na segurança pública solicitada pelos governadores de estado que permite a interferência do executivo federal no poder do executivo estadual, sendo de caráter excepcional só nos casos previstos em texto constitucional, tendo como regra geral a não intervenção da União nos Estados.

Quando da decretação de uma intervenção Federal em um dos Estados-Membros o controle dos órgãos estatais de segurança é assumido por um militar federal denominado de interventor que atuará, em conjunto com as Forças Armadas, para a promoção da manutenção ou restabelecimento da normalidade constitucional da garantia da lei e da ordem em locais determinados.

Ressalta que ao cumprir seu objetivo na área intervencionada a presença das Forças Armadas não ter mais justificativa de continuidade e os trabalhos devem ser finalizados e o controle da segurança pública devolvida ao chefe do executivo estadual para prosseguimento das suas obrigações.

Outra hipótese que condicionam o emprego das Forças Armadas voltadas a ações de segurança pública é em eventos oficiais de interesse nacional com presença de representantes de Chefe de Estados Estrangeiros, devidamente atuando em cooperação com as autoridades locais, sendo regulamentado pelo Decreto 3.897 (BRASIL, 2001).

Dessa forma vale salientar que o emprego dos Militares das três Forças Armadas não é destinado para atividades voltadas à área de segurança pública interna e sim para confrontos terrestres, aéreos e marítimos, em prol da soberania nacional ou em confrontos de iminente confronto de guerra declarada, sendo que o uso reiterado na segurança pública dos Estados- membros não é o objetivo fim das Forças Armadas Brasileiras.

\section{OBJETIVO}

Proporcionar destaque aos principais pontos sobre o amparo legal na decretação das operações de garantia da lei e da ordem e explica o surgimento nas questões de maior relevo quando

da utilização das forças armadas na decretação das operações de garantia da lei e da ordem por um dos Chefes dos Três Poderes.

\section{METODOLOGIA}

O presente projeto foi realizado por meio do método dedutivo, que parte da compreensão da regra geral para então compreender os casos específicos, por ser um processo de análise de informações que nos leva a uma conclusão, ou seja, usa-se da dedução para encontrar o resultado final. (VERGARA, 2010)

O trabalho se realizará com abordagem de cunho qualitativo, pois segundo Lakatos e Marconi (2004, p. 269), este tipo de metodologia analisa e interpreta aspectos mais profundos, demonstrando a complexidade do comportamento humano, ou seja, proporciona uma análise mais detalhada sobre hábitos e tendências do comportamento humano.

Com base nos objetivos a pesquisa será exploratória. Tendo como objetivo proporcionar maior familiaridade com o problema, com vista a torná-lo mais explicito ou construir hipóteses com o aprimoramento de ideias e descoberta de intuições.

Em relação aos procedimentos técnicos a pesquisa será bibliográfica, pois na visão de Lakatos e Marconi (2004), abrange toda a bibliografia já tornada pública em relação ao tema estudado, desde as publicações avulsas, jornais, revistas, livros.

Sua finalidade é colocar o pesquisador em contato direto com tudo o que foi escrito, dito ou filmado sobre determinado assunto para um melhor atendimento da sociedade acadêmica em geral.

Esta pesquisa marca bibliograficamente as visões de autores ligados ao Direito Constitucional, Direito Humanos e a Segurança Pública Nacional, os quais procuram mostrar de que forma podemos discutir a utilização das Forças Armadas no caso de decretação das operações de garantia da lei e da ordem pelos Chefes dos Poderes Executivo, Legislativo ou Judiciário e mostrar a evolução legislativa que permitiu o emprego dos militares na segurança pública dos Estados-membros.

\section{RESULTADOS E DISCUSSÃO PRELIMINARES}

Dentro de sua forma de desempenhar suas funções, às Forças Armadas utiliza o Exército para combate terrestre, Marinha para defesa marítima e a Aeronáutica na segurança e proteção do espaço aéreo em prol da garantia da soberania nacional e do estado democrático de direito.

Nas ocasiões de extrema e insustentável necessidade da decretação da Garantia da lei e da Ordem as Forças Armadas serão empregadas para substituir a missão primária a ser desempenhada pelos integrantes dos órgãos de segurança pública, conforme previsto no Artigo 144, da Constituição Federal (BRASIL, 1988):

Art. 144. A segurança pública, dever do Estado, direito e responsabilidade de todos, é exercida para a preservação da ordem pública e da incolumidade das pessoas e do patrimônio, através dos seguintes órgãos:

I - polícia federal;

II - polícia rodoviária

federal; III - polícia ferroviária federal; IV polícias civis;

V - polícias militares e corpos de bombeiros militares.

Segundo o Ministro Luís Roberto Barroso (2008), Subsidiaria e eventualmente às Forças Armadas podem ser convocadas para atuarem nos centros urbanos, caso algum dos legitimados na Constituição Federal (BRASIL, 1988) venham a solicitar, para a defesa do Estado brasileiro e das instituições democráticas, tendo como hipótese excepcional a utilização dos militares na segurança públicas dos Estados-membros no policiamento Ostensivo e de choque, por solicitação de governador de Estado membro.

Para efetivamente ter a atuação das Forças Armadas na segurança pública, deve-se considerar a permissão constitucional do Artigo 142 (BRASIL, 1988), que diz:

Art. 142. As Forças Armadas, constituídas 
pela Marinha, pelo Exército e pela Aeronáutica, são instituições nacionais permanentes e regulares, organizadas com base na hierarquia e na disciplina, sob a autoridade suprema do Presidente da República, e destinam-se à defesa da Pátria, à garantia dos poderes constitucionais e, por iniciativa de qualquer destes, da lei e da ordem . (grifos nossos)

Conforme destaque acima, o artigo 142 da nossa carta maior estabelece que umas das atribuições das Forças Armadas é a garantia da lei e da ordem, sendo tal premissa regulamentada pela Lei Complementar $n^{\circ} 136$ (BRASIL, 2010), a qual dispõe sobre as normas gerais para organização, o preparo e emprego das Forças Armadas:

Art. 15. O emprego das Forças Armadas na defesa da Pátria e na garantia dos poderes constitucionais, da lei e da ordem, e na participação em operações de paz, é de responsabilidade do Presidente da República, que determinará ao Ministro de Estado da Defesa a ativação de órgãos operacionais, observada a seguinte forma de subordinação:

\section{[...]}

$\S 1^{\circ}$ Compete ao Presidente da República à decisão do emprego das Forças Armadas, por iniciativa própria ou em atendimento a pedido manifestado por quaisquer dos poderes constitucionais, por intermédio dos Presidentes do Supremo Tribunal Federal, do Senado Federal ou da Câmara dos Deputados. § $2^{\circ}$ A atuação das Forças Armadas, na garantia da lei e da ordem, por iniciativa de quaisquer dos poderes constitucionais, ocorrerá de acordo com as diretrizes baixadas em ato do Presidente da República, após esgotados os instrumentos destinados à preservação da ordem pública e da incolumidade das pessoas e do patrimônio, relacionados no art. 144 da Constituição Federal.

$\S \quad 3^{\circ} \quad$ Consideram-se esgotados os instrumentos relacionados no art. 144 da

Constituição Federal quando, em determinado momento, forem eles

formalmente reconhecidos pelo respectivo Chefe do Poder Executivo Federal ou Estadual como indisponíveis, inexistentes ou insuficientes ao desempenho regular de sua missão constitucional.

$\S 4^{\circ}$ Na hipótese de emprego nas condições previstas no $\S 3$ deste artigo, após mensagem do Presidente da República, serão ativados os órgãos operacionais das Forças Armadas, que desenvolverão, de forma episódica, em área previamente estabelecida e por tempo limitado, as ações de caráter preventivo e repressivo necessárias para assegurar o resultado das operações na garantia da lei e da ordem.

$\S 5^{\circ}$ Determinado o emprego das Forças Armadas na garantia da lei e da ordem, caberá à autoridade competente, mediante ato formal, transferir o controle operacional dos órgãos de segurança pública necessários ao desenvolvimento das ações para a autoridade encarregada das operações, a qual deverá constituir um centro de coordenação de operações, composto por representantes dos órgãos públicos sob seu controle operacional ou com interesses afins.

A situação de esgotamento dos instrumentos destinados à preservação da ordem pública; da isenção de perigo as pessoas; e de danos ao patrimônio configuraram situações alarmante em que a Segurança Pública ficou em total indisponibilidade ao desempenho regular de sua missão constitucional, tendo que utilizar subsidiariamente o emprego das Forças Armadas na garantia da lei e da ordem, em caráter excepcional, episódico e temporário, sendo que tal solicitação interventiva pode gerar o mais enfraquecimento das atividades básicas desempenhadas pelos órgãos da segurança públicas nos Estados.

Existe a regulamentação do Decreto $\mathrm{n}^{0} 3.897$ (BRASIL, 2001), que possibilita com destaque à relevância a hipótese de exercer o poder de polícia pelos militares:

Art. $3^{\circ}$. Na hipótese de emprego das Forças Armadas para a garantia da lei e da ordem, objetivando a preservação da ordem pública e da incolumidade das pessoas e do patrimônio, porque esgotados os instrumentos a isso previstos no art. 144 da Constituição, lhes incumbirá, sempre que se faça necessário, desenvolver as ações de polícia ostensiva, como as demais, de natureza preventiva ou repressiva, que se incluem na competência, constitucional e legal, das Polícias Militares, observados os termos e limites impostos, a estas últimas, pelo ordenamento jurídico.

O Decreto $n^{\circ} 3.897$ (BRASIL, 2001) trouxe requisitos legais para que as atuações dos militares das Forças Armadas venham direcionar a garantia da lei e da ordem para preservação da ordem pública, incolumidade das pessoas e do patrimônio, como uma forma de auxiliar o restabelecimento da normalidade da segurança pública.

\section{MISSÕES INSTITUCIONAIS DOS MILITARES DAS FORÇAS ARMADAS}

A missão típica dos militares das forças armadas é a defensa da Pátria, Soberania nacional, a lei e a ordem, por iniciativa de qualquer dos poderes constitucionais, cooperarem com a defesa civil e com o desenvolvimento nacional e participar de operações internacionais, como a missão de paz da Organização das Nações Unidas no Haiti, na forma determinada pelo Presidente da República.

A missão atípica das Forças Armadas é voltada ao auxilio no combate de epidemias, no emprego de conserto de rodovias federais, como também, missões preconizadas no Decreto $\mathrm{n}^{\circ}$ 3.897 (BRASIL, 2001):

Art.16. Cabe às Forças Armadas, além de outras ações pertinentes, também como atribuições subsidiárias, preservadas as competências exclusivas das polícias judiciárias, atuar, por meio de ações preventivas e repressivas, na faixa de fronteira terrestre, no mar e nas águas interiores, independentemente da posse, da propriedade, da finalidade ou de qualquer 
gravame que sobre ela recaia, contra delitos transfronteiriços e ambientais, isoladamente ou em coordenação com outros órgãos do Poder Executivo, executando as ações de: I patrulhamento;

II - revista de pessoas, de veículos terrestres, de embarcações e de aeronaves; $\mathrm{e}$

III - prisões em flagrante delito.

Assim em apertada síntese, estes são os fatos que relatam as missões institucionais das Forças Armadas, diante da conjuntura nacional. (FREITAS, 2014)

\section{Estrutura das Atividades de Garantia da Lei e da Ordem}

A estrutura das atividades de garantia da lei e da ordem a ser desempenhada pelas Forças Armadas poderá ser rapidamente utilizada por uma das Brigadas de Infantaria Leve, situadas em quase todas as capitais do Brasil, por terem treinamento específico, equipamento para atuação da missão, armamentos e dispositivos para controle de distúrbios, podendo ser deslocadas para qualquer ponto nacional.

Nos quadros dos guardeis militares existem grupamentos operacionais que realizam tarefas

desempenhadas nas missões de garantia da lei e da ordem, como é o caso dos Fuzileiros Navais, da Polícia do Exército e dos Batalhões de Infantaria Aeronáutica, a depender da especificação da utilização de cada força armada para garanti e devolver a normalidade institucional aos cidadãos brasileiros.

\section{Poder de Polícia a ser Exercidos pelas Forças Armadas}

O poder de polícia a ser exercido pelos militares das forças armadas é uma faculdade de que a administração pública dispõe para condicionar e restringir a disposição, a atividades, o gozo dos bens e direitos individuais coletivos ou do Estado. Hely Lopes Meirelles (2003, p. 2014), define o que seria o poder de polícia:

O poder de polícia é a faculdade discricionária de que dispõe a Administração Pública em geral, para condicionar e restringir o uso e gozo de bens ou direitos individuais, em benefício da coletividade ou do próprio Estado. (MEIRELLES, 2003).

Como também salienta Álvaro Lazzarini (1999, p. 39), da distinção de polícia e poder de poder de polícia para garantia da lei e da ordem na segurança pública:

Polícia é algo em concreto, é um conjunto de atividades coercitivas exercidas na prática dentro de um grupo social, o poder de polícia é uma faculdade, uma possibilidade, um direito que o Estado tem de, através da polícia, que é uma força organizada, limitar as atividades nefastas dos cidadãos, sendo ainda que a atuação do órgão policial é adstrita à sua competência legal porque a primeira condição de legalidade da atuação de um organismo é a competência legal dos seus agentes (LAZZARINI, 1999)

Verifica-se uma divergência, para a aplicação do poder de polícia pelas Forças Armadas, entre os textos do Decreto, da Lei Complementar e da Constituição, pois o decreto não poderia regulamentar a forma como a lei será cumprida, sendo que a Constituição (BRASIL, 1988) e suas bases não podem ser alteradas por um decreto.
As Forças Armadas têm o dever constitucional de assegurar e manter ao Estado Brasileiro estabilidade para que desenvolva suas atividades e venha a promover a garantia institucional aos poderes constituintes, sendo composta pelo Exército, Marinha e a Aeronáutica, dotadas de um grande poder armamentista.

Dentro dos princípios do Estado Democrático de Direito às Forças Armadas, constitucionalmente, possuem como pilares básicos de sua organização a hierarquia e na disciplina, são um corpo especial da administração por sua militarização, tendo como chefe imediato o Presidente da República. (FERREIRA FILHO, 2002, p. 235)

Pode-se Destacar a Intervenção federal na segurança pública solicitada pelos governadores de estado que permite a interferência do executivo federal no poder do executivo estadual, sendo de caráter excepcional só nos casos previstos em texto constitucional, tendo como regra geral a não intervenção da União nos Estados.

Quando da decretação de uma intervenção Federal em um dos Estados-Membros o controle dos órgãos estatais de segurança é assumido por um militar federal denominado de interventor que atuará, em conjunto com as Forças Armadas, para a promoção da manutenção ou restabelecimento da normalidade constitucional da garantia da lei e da ordem em locais determinados.

Ressalta que ao cumprir seu objetivo na área intervencionada a presença das Forças Armadas não ter mais justificativa de continuidade e os trabalhos devem ser finalizados e o controle da segurança pública devolvida ao chefe do executivo estadual para prosseguimento das suas obrigações.

Outra hipótese que condicionam o emprego das Forças Armadas voltadas a ações de segurança pública é em eventos oficiais de interesse nacional com presença de representantes de Chefe de Estados Estrangeiros, devidamente atuando em cooperação com as autoridades locais, sendo regulamentado pelo Decreto 3.897 (BRASIL, 2001).

Dessa forma vale salientar que o emprego dos Militares das três Forças Armadas não é destinado para atividades voltadas à área de segurança pública interna e sim para confrontos terrestres, aéreos e marítimos, em prol da soberania nacional ou em confrontos de iminente confronto de guerra declarada, sendo que o uso reiterado na segurança pública dos Estados- membros não é o objetivo fim das Forças Armadas Brasileiras.

\section{OBJETIVO}

Proporcionar destaque aos principais pontos sobre o amparo legal na decretação das operações de garantia da lei e da ordem e explica o surgimento nas questões de maior relevo quando da utilização das forças armadas na decretação das operações de garantia da lei e da ordem por um dos Chefes dos Três Poderes.

\section{METODOLOGIA}

O presente projeto foi realizado por meio do método dedutivo, que parte da compreensão da regra geral para então compreender os casos específicos, por ser um processo de análise de informações que nos leva a uma conclusão, ou seja, usa-se da dedução para encontrar o resultado final. (VERGARA, 2010)

O trabalho se realizará com abordagem de cunho qualitativo, pois segundo Lakatos e Marconi (2004, p. 269), este tipo de metodologia analisa e interpreta aspectos mais profundos, demonstrando a complexidade do comportamento humano, ou seja, proporciona uma análise mais detalhada sobre hábitos e tendências do comportamento humano.

Com base nos objetivos a pesquisa será exploratória. Tendo 
como objetivo proporcionar maior familiaridade com o problema, com vista a torná-lo mais explicito ou construir hipóteses com o aprimoramento de ideias e descoberta de intuições.

Em relação aos procedimentos técnicos a pesquisa será bibliográfica, pois na visão de Lakatos e Marconi (2004), abrange toda a bibliografia já tornada pública em relação ao tema estudado, desde as publicações avulsas, jornais, revistas, livros.

Sua finalidade é colocar o pesquisador em contato direto com tudo o que foi escrito, dito ou filmado sobre determinado assunto para um melhor atendimento da sociedade acadêmica em geral.

Esta pesquisa marca bibliograficamente as visões de autores ligados ao Direito Constitucional, Direito Humanos e a Segurança Pública Nacional, os quais procuram mostrar de que forma podemos discutir a utilização das Forças Armadas no caso de decretação das operações de garantia da lei e da ordem pelos Chefes dos Poderes Executivo, Legislativo ou Judiciário e mostrar a evolução legislativa que permitiu o emprego dos militares na segurança pública dos Estados-membros.

\section{RESULTADOS E DISCUSSÃO PRELIMINARES}

Dentro de sua forma de desempenhar suas funções, às Forças Armadas utiliza o Exército para combate terrestre, Marinha para defesa marítima e a Aeronáutica na segurança e proteção do espaço aéreo em prol da garantia da soberania nacional e do estado democrático de direito.

Nas ocasiões de extrema e insustentável necessidade da decretação da Garantia da lei e da Ordem as Forças Armadas serão empregadas para substituir a missão primária a ser desempenhada pelos integrantes dos órgãos de segurança pública, conforme previsto no Artigo 144, da Constituição Federal (BRASIL, 1988):

Art. 144. A segurança pública, dever do Estado, direito e responsabilidade de todos, é exercida para a preservação da ordem pública e da incolumidade das pessoas e do patrimônio, através dos seguintes órgãos:

I - polícia federal;

II - polícia rodoviária federal;

III - polícia ferroviária federal; IV - polícias civis;

$\mathrm{V}$ - polícias militares e corpos de bombeiros militares.

Segundo o Ministro Luís Roberto Barroso (2008), Subsidiaria e eventualmente às Forças

Armadas podem ser convocadas para atuarem nos centros urbanos, caso algum dos legitimados na Constituição Federal (BRASIL, 1988) venham a solicitar, para a defesa do Estado brasileiro e das instituições democráticas, tendo como hipótese excepcional a utilização dos militares na segurança públicas dos Estados-membros no policiamento Ostensivo e de choque, por solicitação de governador de Estado membro.

Para efetivamente ter a atuação das Forças Armadas na segurança pública, deve-se considerar a permissão constitucional do Artigo 142 (BRASIL, 1988), que diz:

Art. 142. As Forças Armadas, constituídas pela Marinha, pelo Exército e pela Aeronáutica, são instituições nacionais permanentes e regulares, organizadas com base na hierarquia e na disciplina, sob a autoridade suprema do Presidente da República, e destinam-se à defesa da Pátria, à garantia dos poderes constitucionais e, por iniciativa de qualquer destes, da lei e da ordem . (grifos nossos)

Conforme destaque acima, o artigo 142 da nossa carta maior estabelece que umas das atribuições das Forças Armadas é a garantia da lei e da ordem, sendo tal premissa regulamentada pela Lei Complementar $n^{\circ} 136$ (BRASIL, 2010), a qual dispõe sobre as normas gerais para organização, o preparo e emprego das Forças Armadas:

Art. 15. O emprego das Forças Armadas na defesa da Pátria e na garantia dos poderes constitucionais, da lei e da ordem, e na participação em operações de paz, é de responsabilidade do Presidente da República, que determinará ao Ministro de Estado da Defesa a ativação de órgãos operacionais, observada a seguinte forma de subordinação: [...]

$\S 1^{\circ}$ Compete ao Presidente da República à decisão do emprego das Forças Armadas, por iniciativa própria ou em atendimento a pedido manifestado por quaisquer dos poderes constitucionais, por intermédio dos Presidentes do Supremo Tribunal Federal, do Senado Federal ou da Câmara dos Deputados. $\S 2^{\circ}$ A atuação das Forças Armadas, na garantia da lei e da ordem, por iniciativa de quaisquer dos poderes constitucionais, ocorrerá de acordo com as diretrizes baixadas em ato do Presidente da República, após esgotados os instrumentos destinados à preservação da ordem pública e da incolumidade das pessoas e do patrimônio, relacionados no art. 144 da Constituição Federal.

$\S \quad 3^{\circ} \quad$ Consideram-se esgotados os instrumentos relacionados no art. 144 da Constituição Federal quando, em determinado momento, forem eles formalmente reconhecidos pelo respectivo Chefe do Poder Executivo Federal ou Estadual como indisponíveis, inexistentes ou insuficientes ao desempenho regular de sua missão constitucional.

$\S 4^{\circ}$ Na hipótese de emprego nas condições previstas no $\S 3$ deste artigo, após mensagem do Presidente da República, serão ativados os órgãos operacionais das Forças Armadas, que desenvolverão, de forma episódica, em área previamente estabelecida e por tempo limitado, as ações de caráter preventivo e repressivo necessárias para assegurar o resultado das operações na garantia da lei e da ordem.

$\S 5^{\circ}$ Determinado o emprego das Forças Armadas na garantia da lei e da ordem, caberá à autoridade competente, mediante ato formal, transferir o controle operacional dos órgãos de segurança pública necessários ao desenvolvimento das ações para a autoridade encarregada das operações, a qual deverá 
constituir um centro de coordenação de operações, composto por representantes dos órgãos públicos sob seu controle operacional ou com interesses afins.

A situação de esgotamento dos instrumentos destinados à preservação da ordem pública; da isenção de perigo as pessoas; e de danos ao patrimônio configuraram situações alarmante em que a Segurança Pública ficou em total indisponibilidade ao desempenho regular de sua missão constitucional, tendo que utilizar subsidiariamente o emprego das Forças Armadas na garantia da lei e da ordem, em caráter excepcional, episódico e temporário, sendo que tal solicitação interventiva pode gerar o mais enfraquecimento das atividades básicas desempenhadas pelos órgãos da segurança públicas nos Estados.

Existe a regulamentação do Decreto $\mathrm{n}^{\circ} 3.897$ (BRASIL, 2001), que possibilita com destaque à relevância a hipótese de exercer o poder de polícia pelos militares:

Art. $3^{\circ}$. Na hipótese de emprego das Forças Armadas para a garantia da lei e da ordem, objetivando a preservação da ordem pública e da incolumidade das pessoas e do patrimônio, porque esgotados os instrumentos a isso previstos no art. 144 da Constituição, lhes incumbirá, sempre que se faça necessário, desenvolver as ações de polícia ostensiva, como as demais, de natureza preventiva ou repressiva, que se incluem na competência, constitucional e legal, das Polícias Militares, observados os termos e limites impostos, a estas últimas, pelo ordenamento jurídico.

O Decreto $n^{\circ} 3.897$ (BRASIL, 2001) trouxe requisitos legais para que as atuações dos militares das Forças Armadas venham direcionar a garantia da lei e da ordem para preservação da ordem pública, incolumidade das pessoas e do patrimônio, como uma forma de auxiliar o restabelecimento da normalidade da segurança pública.

\section{MISSÕES INSTITUCIONAIS DOS MILITARES DAS FORÇAS ARMADAS}

A missão típica dos militares das forças armadas é a defensa da Pátria, Soberania nacional, a lei e a ordem, por iniciativa de qualquer dos poderes constitucionais, cooperarem com a defesa civil e com o desenvolvimento nacional e participar de operações internacionais, como a missão de paz da Organização das Nações Unidas no Haiti, na forma determinada pelo Presidente da República.

A missão atípica das Forças Armadas é voltada ao auxilio no combate de epidemias, no emprego de conserto de rodovias federais, como também, missões preconizadas no Decreto $\mathrm{n}^{\circ}$ 3.897 (BRASIL, 2001):

Art.16. Cabe às Forças Armadas, além de outras ações pertinentes, também como atribuições subsidiárias, preservadas as competências exclusivas das polícias judiciárias, atuar, por meio de ações preventivas e repressivas, na faixa de fronteira terrestre, no mar e nas águas interiores, independentemente da posse, da propriedade, da finalidade ou de qualquer gravame que sobre ela recaia, contra delitos transfronteiriços e ambientais, isoladamente ou em coordenação com outros órgãos do Poder Executivo, executando as ações de: I patrulhamento;
II - revista de pessoas, de veículos terrestres, de embarcações e de aeronaves; e

III - prisões em flagrante delito.

Assim em apertada síntese, estes são os fatos que relatam as missões institucionais das Forças Armadas, diante da conjuntura nacional. (FREITAS, 2014)

\section{ESTRUTURA DAS ATIVIDADES DE GARANTIA DA LEI E DA ORDEM}

A estrutura das atividades de garantia da lei e da ordem a ser desempenhada pelas Forças Armadas poderá ser rapidamente utilizada por uma das Brigadas de Infantaria Leve, situadas em quase todas as capitais do Brasil, por terem treinamento específico, equipamento para atuação da missão, armamentos e dispositivos para controle de distúrbios, podendo ser deslocadas para qualquer ponto nacional.

Nos quadros dos guardeis militares existem grupamentos operacionais que realizam tarefas desempenhadas nas missões de garantia da lei e da ordem, como é o caso dos Fuzileiros Navais, da Polícia do Exército e dos Batalhões de Infantaria Aeronáutica, a depender da especificação da utilização de cada força armada para garanti e devolver a normalidade institucional aos cidadãos brasileiros.

\section{PODER DE POLÍCIA A SER EXERCIDOS PELAS FORÇAS ARMADAS}

O poder de polícia a ser exercido pelos militares das forças armadas é uma faculdade de que a administração pública dispõe para condicionar e restringir a disposição, a atividades, o gozo dos bens e direitos individuais coletivos ou do Estado. Hely Lopes Meirelles (2003, p. 2014), define o que seria o poder de polícia:

O poder de polícia é a faculdade discricionária de que dispõe a Administração Pública em geral, para condicionar e restringir o uso e gozo de bens ou direitos individuais, em benefício da coletividade ou do próprio Estado. (MEIRELLES, 2003).

Como também salienta Álvaro Lazzarini (1999, p. 39), da distinção de polícia e poder de poder de polícia para garantia da lei e da ordem na segurança pública:

Polícia é algo em concreto, é um conjunto de atividades coercitivas exercidas na prática dentro de um grupo social, o poder de polícia é uma faculdade, uma possibilidade, um direito que o Estado tem de, através da polícia, que é uma força organizada, limitar as atividades nefastas dos cidadãos, sendo ainda que a atuação do órgão policial é adstrita à sua competência legal porque a primeira condição de legalidade da atuação de um organismo é a competência legal dos seus agentes (LAZZARINI, 1999)

Verifica-se uma divergência, para a aplicação do poder de polícia pelas Forças Armadas, entre os textos do Decreto, da Lei Complementar e da Constituição, pois o decreto não poderia regulamentar a forma como a lei será cumprida, sendo que a Constituição (BRASIL, 1988) e suas bases não podem ser alteradas por um decreto.

Vale salientar que uma Lei Complementar, com todos os ritos legislativos respeitados, não pode criar um novo órgão para atuar na segurança pública dos Estados-Membros, uma vez que a Constituição Federal (BRASIL, 1988) já definiu quais devem 
exercer tal papel na segurança institucional, sendo por oportuno elabora uma proposta de emenda constitucional para preservar e proteger os ditames constitucionais sem relativizá-los.

Mesmo assim pelo mau emprego, por diversas vezes desnecessário, das Forças Armadas, os preceitos constitucionais e legais não foram obedecidos, como por exemplo, na Operação Rio 2004, sem que tenha sido decretadas situações de anormalidade previstas na Constituição.

Para o doutrinador Carlos Henrique Reinninger (2004, p.103), o Decreto n. ${ }^{\circ} 3.897$ (BRASIL, 2001) utiliza de forma errada as Forças Armadas que são empregadas, pois não há amparo legal para as suas investiduras e na prática é uma intervenção federal sem atender formalidades preconizadas na Constituição da Republica Federativa do Brasil de 1988.

Para Franklimberg Ribeiro de Freitas (2014), o emprego, engajamento e utilização dos membros militares das Forças Armadas na segurança pública urbana, em situação de normalidade, conforme o Decreto $n^{\circ} 3.897$ (BRASIL, 2001) vem provocando potenciais problemas consideráveis, pois prisões podem ser consideradas ilegais; militares podem ser acusados de abuso de autoridade; confrontos que podem gerar processos criminais na Justiça Comum em desobediência do objetivo fim de emprego dos militares.

Porém, deve-se considerar que a falência dos órgãos de segurança publica nos estados está fadada ao fracasso e o cidadão de bem não pode ficar a mercê da criminalidade que a cada dia vem exponencialmente aumentando, por isso governos estaduais se socorrer do emprego das Forças Armadas, como uma última instância para retomada da estabilidade na segurança pública, pelo princípio da Supremacia do Interesse público em benefício da coletividade.

\section{CONSIDERAÇÕES FINAIS}

O emprego das Forças Armadas em missões de segurança do País encontra-se respaldado nas Constituições Federais promulgadas ao longo de nossa história. Esse tipo de aplicação de tropas federais em ações de Garantia da Lei e da Ordem constitui-se em um instrumento que o Estado Brasileiro possui para utilizá-lo quando os Órgãos de Segurança Pública Federais, Estaduais ou Municipais encontrarem-se incapacitados para solucionar os problemas surgidos.

As operações de garantia da lei e da ordem, a partir da Constituição Federal de 1988, passaram a ser normatizadas por leis complementares que tratam da organização, preparação e emprego das Forças Armadas. Naturalmente, em razão dos diversificados tipos de emprego dos militares nesses tipos de ações, houve a necessidade de aperfeiçoamento do respaldo legal, a fim de se evitar problemas subsequentes de ações judiciais contra seus integrantes.

Nos momentos da vida nacional que houve a necessidade de se aumentar a segurança pública em importantes eventos no Brasil ou por motivo de grave perturbação da ordem pública as Forças Armadas sempre foram convocadas pela Presidência da República, para participar dessas ações e estabelecer garantias constitucionais aos brasileiros, como também, as visitantes estrangeiros.

Salienta-se que o emprego das Forças Armadas em ações de Garantia da Lei e da Ordem deve ser o último instrumento a ser adotado, depois de esgotadas todas as possibilidades de emprego dos Órgãos de Segurança Pública, que são por vocação e competência, destinados à preservação da segurança em nosso país.

Cabendo às Forças Armadas somente restabelecer a ordem e as condições para a volta da atuação te tais órgãos. Por fim, o Poder Militar é capaz de neutralizar, temporariamente, os efeitos de uma determinada situação que afete os poderes constitucionais, a lei e a ordem, mas só a atuação integrada de todas as expressões do Poder da Segurança Nacional será capaz de eliminar as reais causas do problema.

\section{REFERÊNCIAS BIBLIOGRÁFICAS:}

BARROSO, Luís Roberto. Segurança pública: atuação das forças armadas tem de ser excepcional . Consultor Jurídico, 2008.

BRASIL . Decreto no 3.897, de 24 de agosto de 2001. Brasília, DF: Câmara dos deputados. Fixa as diretrizes para o emprego das Forças Armadas na garantia da lei e da ordem, e dá outras providências.

Constituição (1988). Constituição da República

Federativa do Brasil . Brasília, DF: Senado, 1988.

Lei Complementar $n^{\circ}$ 136, de 25 de agosto de 2010. Dispõe sobre as normas gerais para a organização, o preparo e o emprego das Forças Armadas.

FERREIRA FILHO, Manoel Gonçalves. Curso de Direito Administrativo . 28. ed. São Paulo: Saraiva, 2002.

FREITAS . Franklimberg Ribeiro de. Operação na Faixa de Fronteira Intensificação da Presença do Estado e seu Respaldo Legal . 2014.

LAZZARINI, Álvaro. Estudos de Direito Administrativo . 2. ed. São Paulo: Revista dos Tribunais, 1999. 447 p.

MARCONI, Marina de Andrade; LAKATOS, Eva Maria. Metodologia do trabalho científico . 7. ed. São Paulo: Atlas, 2009.

MEIRELLES, Hely Lopes. Direito Administrativo Brasileiro . 17. ed. São Paulo: Malheiros, 2003.

REINNINGER, Carlos Henrique. Aspectos Jurídicos do emprego das Forças Armadas nas Operações de Garantia da Lei e da Ordem . Rio de Janeiro, 2004.

VERGARA, Sylvia Constant. Projetos e Relatórios de Pesquisa em Administração, 12 $12^{\mathrm{a}}$ ed., São Paulo: Atlas, 2010. 